\title{
SYNTHESIS, CHARACTERIZATION, SWELLING BEHAVIOR AND ANTIMICROBIAL ACTIVITIES OF POLY (N- CYCLOHEXYLACRYLAMIDE-CO- ACRYLAMIDE-CO-2- ACRYLAMIDO-2-METHYLPROPANE SULPHONIC ACID SODIUM SALT) ZINC OXIDE NANOCOMPOSITE HYDROGELS
}

\author{
K. Bharathi ${ }^{1}$ and P. Pazhanisamy ${ }^{2, *}$ \\ ${ }^{1}$ Research and Development Centre, Manonmaniam Sundaranar University, \\ Tirunelveli-627012, Tamil Nadu,India \\ ${ }^{2}$ Department of Chemistry, Sir Theagaraya College, Chennai-600021, Tamil Nadu, India \\ E-mail: p_pazhanisamy@yahoo.com
}

\begin{abstract}
Poly(N-cyclohexylacrylamide-co-acrylamide-co-2-acrylamido-2-methylpropane sulphonic acid sodium salt) Zinc oxide $(\mathrm{ZnO})$ nanocomposite hydrogels were synthesized by in situ free-radical copolymerization in aqueous Methanol at $60^{\circ} \mathrm{C}$ using Ammonium persulphate (APS) as the initiator and N,N'- methylenebisacrylamide (MBA) as a crosslinker . The N-cyclohexylacrylamide (NCA) and acrylamide (AM) monomers were fixed as 50:50 w/w and the amount of sodium salt of the 2-acrylamido-2-methylpropane sulphonic acid (AMPSNa) is varied. Characterization of this polymer matrix using FT-IR, SEM/EDX and XRD indicated the presence of $\mathrm{ZnO}$ nanoparticles. The gravimetric method was adopted to study the swelling behavior of $\mathrm{ZnO}$ Hydrogels. The $\mathrm{ZnO}$ nanocomposite hydrogels showed potent antimicrobial activity on pathogenic bacteria Escherichia coli and Staphylococcus aureus and fungi Candida albicans.
\end{abstract}

Keywords: Hydrogels, Nanocomposites, swelling behavior, Antimicrobial activity

(C) RASĀYAN. All rights reserved

Hydrogels are three-dimensionally cross-linked macromolecular hydrophilic polymeric materials. Hydrogels can absorb ten to hundred times of water and can retain a significant amount of water without dissolution. Hydrogels draw attention in the past five decades because of their wide range of applications $^{1,2}$ in various fields in academic and industrial research. ${ }^{3-6} \mathrm{ZnO}$ can be utilized in many products such as pharmaceuticals, rubber, cosmetics, food and solar cells ${ }^{7}$ due to their remarkable properties like UV protection, thermal conductivity, antimicrobial activity and higher binding energy capacity.

Nano zinc has many advantages and better performance compared to bulk size zinc powder. ${ }^{8}$ The incorporation of metal oxide nanoparticles $(\mathrm{ZnO})$ in the hydrogels seems to be an innovation route to the design of unconventional materials. The higher toxicity of $\mathrm{ZnO}$ nanoparticles need to be reduced and more biocompatible by means of incorporating with hydrogels keeping the gradual release intact rather than burst release. ${ }^{9}$ Hydrogels can swell to the profitable amount when placed into a different environment such as particular $\mathrm{pH}$, temperature, electric field, pressure, distinct molecule or light. ${ }^{10-16}$ Nanocomposite hydrogels are hybrid materials which comprise of nanometric dimensions dispersed in a polymer matrix with inorganic substances. Nanocomposite hydrogels have at least two components that showed a synergistic effect in the desired fields.

Rasayan J. Chem., 11(4), 1721-1728(2018)

http://dx.doi.org/10.31788/RJC.2018.1142072 
The interactions between these components may be covalent, ionic or donor-acceptor characters which are stabilized by hydrophilic interactions, Interpenetrating polymer networks produced by macromolecular chain entanglements and hydrogen bonds. ${ }^{17}$ The $\mathrm{ZnO}$ nanocomposite hydrogels have a greater research interest in industries due to the versatile properties. Their properties lead to potential applications in the field of numerous physical and biomedical sectors. ${ }^{18} \mathrm{ZnO}$ nanoparticles enhance the antibacterial activity and blood clotting ability of hydrogels. $\mathrm{ZnO}$ composite bandages improve the wound healing and collagen deposition rate. ${ }^{19}$ The $\mathrm{pH}$ and salinity affect the swelling behavior of $\mathrm{ZnO}$ nanocomposite. ${ }^{20}$ The $\mathrm{ZnO}$ nanocomposite hydrogels were synthesized by in situ polymerization of $\mathrm{N}$ cyclohexyl acrylamide, acrylamide and sodium salt of 2-acryl amido -2-methylpropanesulphonic acid (AMPSNa) .The $\mathrm{ZnO}$ nanocomposite hydrogels were characterized by FT-IR, XRD SEM-EDX. The swelling behavior and antimicrobial activity were also studied.

\section{EXPERIMENTAL}

Acrylamide was purchased from Merck. Ammonium persulphate (APS), N,N'-methylenebisacrylamide (MBA) 2-acrylamido-2-methylpropane sulphonic acid (AMPS) and $\mathrm{ZnO}$ nanoparticles were supplied by Sigma Aldrich . AMPSNa was prepared by neutralization of 2-acrylamido-2-methylpropanesulphonic acid (AMPS) by sodium hydroxide. N-cyclohexyl acrylamide (NCA) was prepared by a procedure described by Pazhanisamy et al. ${ }^{21}$

\section{Preparation of Zinc Oxide Nanocomposite Hydrogels}

The Zinc oxide nanocomposite hydrogels were prepared by free radicals cross-linking copolymerization. Monomers NCA ( $0.5 \mathrm{~g}), \mathrm{AM}(0.5 \mathrm{~g})$ and $\mathrm{AMPSNa}(0.1,0.3,0.5$ and $0.7 \mathrm{~g})$ were added to the well-dispersed $\mathrm{ZnO}$ nanoparticles solution followed by addition of APS $(0.05 \mathrm{~g})$ as initiator and MBA $(0.05 \mathrm{~g})$ as a crosslinker in 3:1 methanol-water mixture at room temperature. They were purged with nitrogen gas for 20 minutes then heated to $60^{\circ} \mathrm{C}$ in a thermostatic water bath and polymerization was conducted for 24 hours .The synthesized nanocomposite hydrogels were dried at $50^{\circ} \mathrm{C}$.

\section{Swelling Behavior}

In order to investigate the swelling behavior, the swelling tests of $\mathrm{ZnO}$ nanocomposite hydrogels were carried out by placing the dry hydrogels in water at room temperature. The water intake of dry hydrogel was determined by weighing the gels after wiping gently with tissue paper at particular time intervals. The percentage swelling of the samples was determined by applying the following equation,

$$
\mathrm{Ds} \%=\frac{\mathrm{Ws}-\mathrm{Wd}}{\mathrm{Wd}} \times 100
$$

Ws is the weight of the swollen gel at a given time and Wd is the weight of the dry gel. DS\% is the degree of swelling.

\section{Kinetic study of ZnO Nanocomposite Hydrogels}

$$
\mathrm{F}_{\mathrm{swp}}=\mathrm{Kt}^{\mathrm{n}}
$$

Where $\mathrm{K}$ is the swelling constant, $\mathrm{t}$ is the time and $\mathrm{n}$ is swelling exponent.

\section{Antimicrobial Studies}

The bacterial culture medium was used agar medium which consists of $2.0 \mathrm{~g}$ of beef extract, $17.5 \mathrm{~g}$ of casein hydrolysate, $1.5 \mathrm{~g}$ starch and $17.0 \mathrm{~g}$ agar dissolved in 1 liter of distilled water and $\mathrm{pH}$ adjusted to neutral. The contents were autoclaved at $15 \mathrm{lbs}$ pressure at $121^{\circ} \mathrm{C}$ for 15 minutes. The sterilized media were poured into $100 \mathrm{~mm}$ Petri dishes. After 30 minutes, the culture medium was inoculated with the test organisms. Petri dishes containing $20 \mathrm{ml}$ Muller Hinton medium were seeded with 24 hours culture of bacteria and fungi and spread well with sterile swabs. Wells were cut and $20 \mu \mathrm{l}(100 \mathrm{mg})$ of the sample along with standard antibacterial and antifungal agents containing disc was placed on to an agar plate. 
Amikacin and ketoconazole were used as a standard antibacterial and antifungal agents respectively. DMSO was used as a control. The plates were then inoculated at $37^{\circ} \mathrm{C}$ for 24 hours. The zone of inhibition was measured and expressed in millimeter.

\section{FT-IR Spectral Characterization}

\section{RESULTS AND DISCUSSION}

The FT-IR spectrum of poly(NCA-co-AM/AMPSNa) ZnO nanocomposite hydrogel is shown in Fig.-1. A broad peak corresponding to NH stretching of NCA was observed around $3433.64 \mathrm{~cm}^{-1}$. The peak observed at $1639.2 \mathrm{~cm}^{-1}$ corresponds to $\mathrm{C}=\mathrm{O}$ stretching of NCA. The characteristic peak at $1538.92 \mathrm{~cm}^{-1}$ corresponds to NH bending vibration of amides. The peak at $2929.34 \mathrm{~cm}^{-1}$ is due to $\mathrm{C}-\mathrm{H}$ stretching of the polymer backbone. The peak at $1215.9 \mathrm{~cm}^{-1}, 1041.37 \mathrm{~cm}^{-1} 620.00 \mathrm{~cm}^{-1}$ corresponds to asymmetric stretching of $-\mathrm{SO}_{2}$, symmetric stretching of the $-\mathrm{SO}_{2}$ group and $\mathrm{C}-\mathrm{S}$ stretching of AMPSNa respectively 21. The IR absorption at $433.90 \mathrm{~cm}^{-1}$ corresponds to $\mathrm{ZnO}$ stretching confirms the incorporation of $\mathrm{ZnO}$ into the polymer matrix. The above IR spectral analysis confirmed the presence of monomeric units in the crosslinked hydrogel.

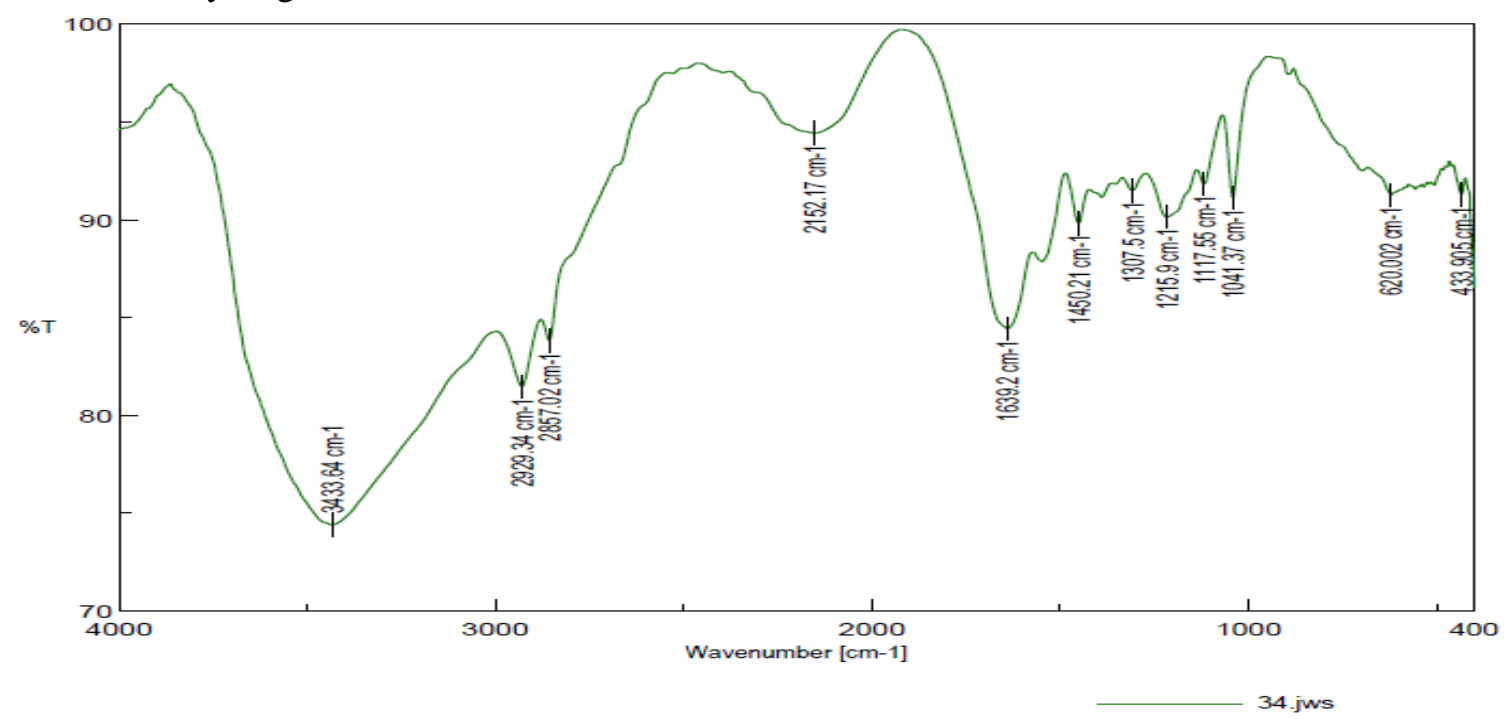

Fig.-1: FT-IR Spectra of Poly(NCA-co-AM-AMPSNa) ZnO Nanocomposite Hydrogel

\section{Swelling Behavior}

Swelling capacity of the hydrogels under investigation in distilled water and the water uptake by hydrogels was observed for an extended period of time till equilibrium was reached. DS\% of poly (NCAco-AM-AMPSNa) $\mathrm{ZnO}$ nanocomposite hydrogels with different concentration of AMPSNa at room temperature was determined and are shown in Fig.-2.The hydrogels swelled rapidly in water and attained equilibrium. It is observed from the figure that the swelling capacity of hydrogels increased along with the increasing amount of AMPSNa. This is due to the increase in hydrophilic groups such as $\mathrm{NH}_{2}, \mathrm{C}=\mathrm{O}$, $\mathrm{SO}_{3} \mathrm{Na}$ Cand increases in hydrodynamic free volume to accommodate more amount of the solvent molecules. The swelling is driven by the repulsion of hydrophilic groups inside the network and hence osmotic pressure increases. The difference in osmotic pressure between the gels and the external solution the swelling rate gradually increases until the equilibrium swelling is reached. Strong polyelectrolyte gel containing sulphonic acid groups have a high degree of ionization. As the concentration of AMPSNa increases, the swelling behavior also increases due to the additional osmotic pressure develops that expands the gel network further. In addition, higher AMPSNa content enhanced the hydrophilicity of the hydrogels causing a higher absorption of water.

\section{Effect of AMPSNa concentration}

The effect of monomer concentration on the swelling capacity of the hydrogel was studied by varying the amount of AMPSNa from $0.1 \mathrm{~g}$ to $0.7 \mathrm{~g}$ (Fig.-2). As the monomer concentration of AMPSNa molecules 
RASĀYAN J. Chem.

Vol. 11 | No. 4 |1721 - 1728| October - December | 2018

into the polymer matrix which consequently increases the water absorbency and also AMPSNa content increases the hydrophilicity of the gel. ${ }^{22}$ The plots of $\mathrm{LnF}$ against LnT (Fig.-3) gives a straight line whose slope is " $n$ ", which is equal to $0.6945,0.7195,0.7845$ and 0.8139 (Table-1) .These values of " $n$ " is in the range between $0.50<\mathrm{n}<1.00$ which indicates that the diffusion is non-Fickian. In the nonFickian diffusion mechanism, diffusion and relaxation are said to be isochronal effective.

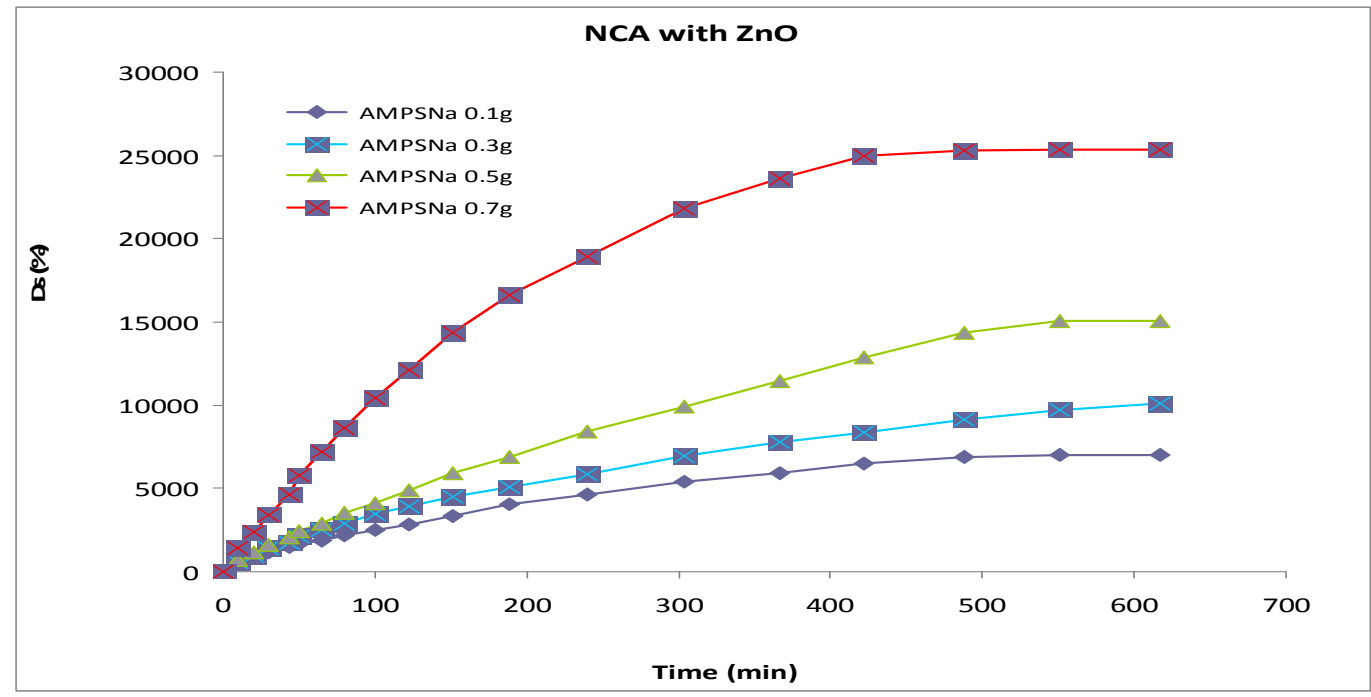

Fig. -2: Swelling Behavior of Poly (NCA-co-AM/AMPSNa) ZnO Nanocomposite Hydrogels

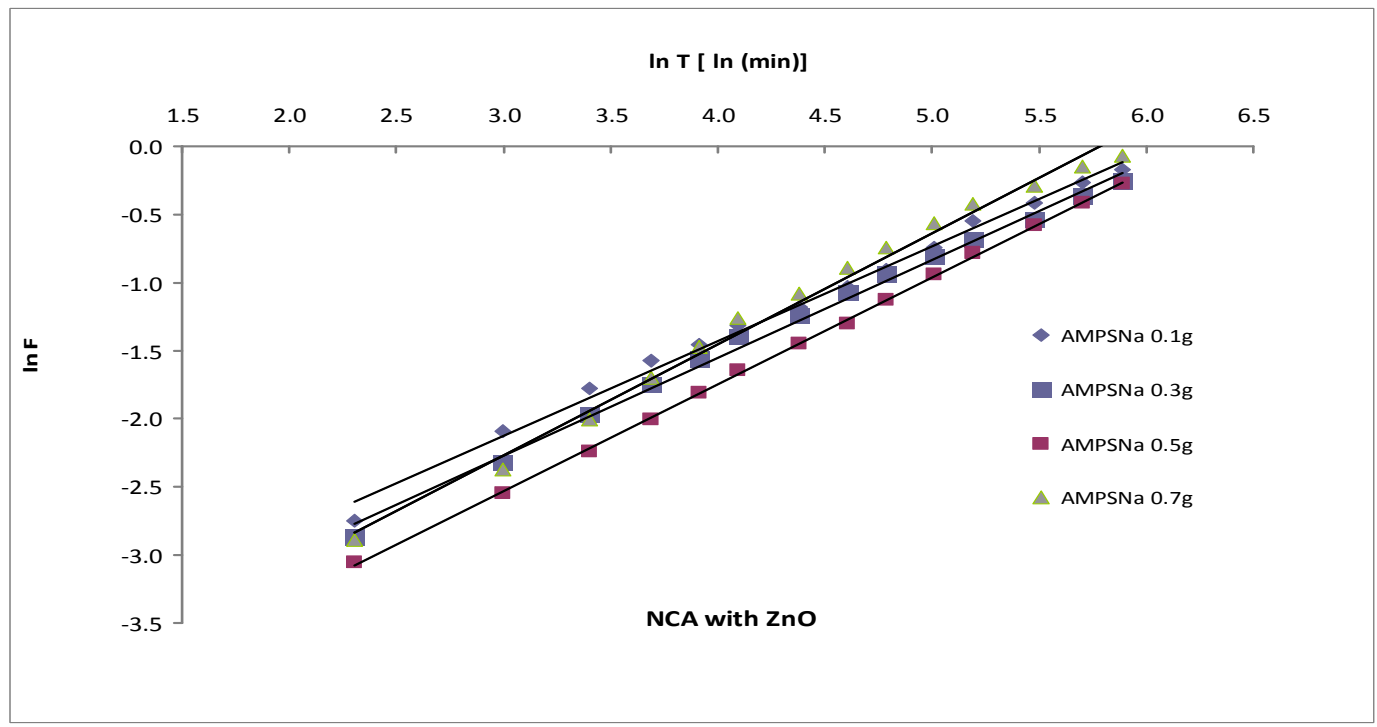

Fig. -3: Plot of ln F vs ln T of Poly (NCA-co-AM/AMPSNa) ZnO Nanocomposite Hydrogels

Table-1: Maximum Swelling and Diffusion Parameters of Poly (NCA-co-AM/AMPSNa) ZnO Nanocomposite Hydrogels

\begin{tabular}{c|c|c|c|c}
\hline S. No. & $\begin{array}{c}\text { Weight of } \\
\text { AMPSNa (g) }\end{array}$ & Max. Ds \% & 'n' value & "k" value \\
\hline 1 & 0.1 & 07042 & 0.6945 & -4.2070 \\
\hline 2 & 0.3 & 10085 & 0.7195 & -4.4274 \\
\hline 3 & 0.5 & 15082 & 0.7845 & -4.8834 \\
\hline 4 & 0.7 & 25348 & 0.8139 & -4.7082 \\
\hline
\end{tabular}




\section{X-Ray Diffraction Studies}

The XRD pattern showed the $\mathrm{ZnO}$ nanocomposite hydrogel (Fig.-4) $2 \theta$ values range from 20 to $70^{\circ}$.It is also observed that 2 theta values of about $34^{\circ}, 37^{\circ}, 39^{\circ}, 44^{\circ}, 64^{\circ}$ and $68^{\circ}$ planes of zincite phase of $\mathrm{ZnO}$ nanoparticles ${ }^{23-25}$ in $\mathrm{ZnO}$ nanocomposite hydrogels. A wide peak between 20 to $30^{\circ}$ is due to the polymer networks. The XRD analysis showed the nanocomposite material is more amorphous in nature.

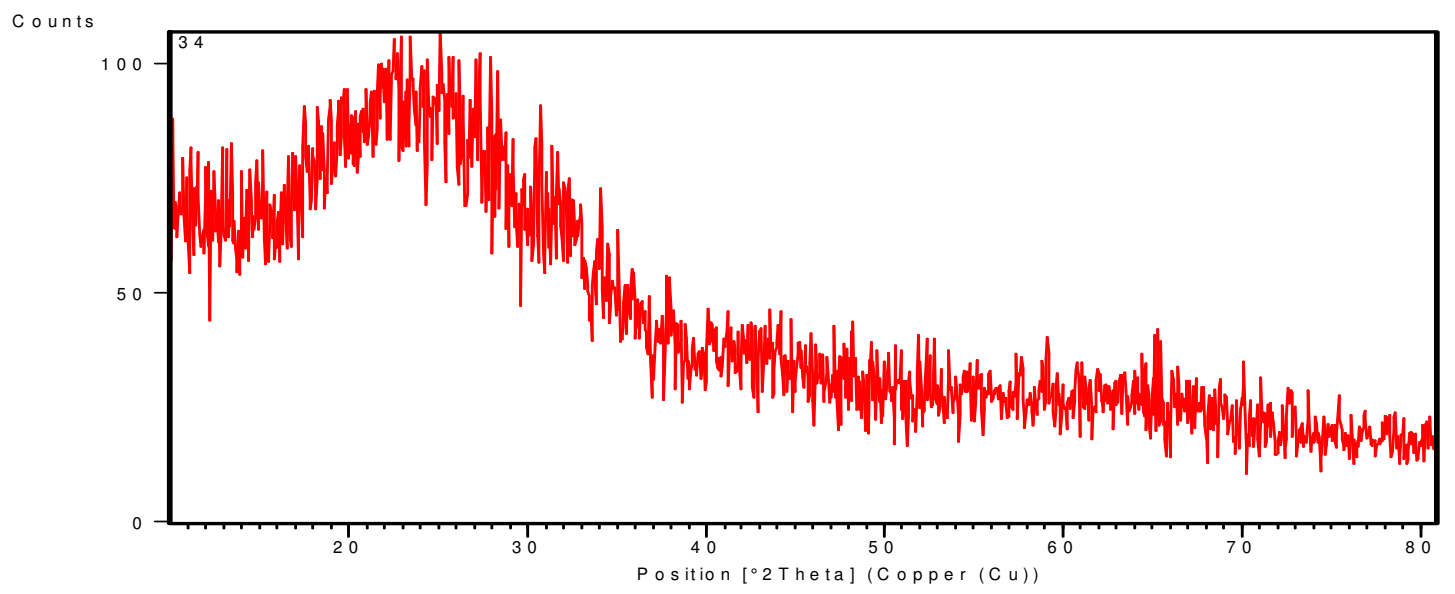

Fig.- 4: XRD of Poly( NCA-co-AM/AMPSNa) ZnO Nanocomposite Hydrogel

\section{SEM/EDX Analysis}

The surface morphology of $\mathrm{ZnO}$ nanocomposite hydrogels was examined under SEM which showed the uniform dispersion of $\mathrm{ZnO}$ nanoparticles in the hydrogel matrix Fig.-5. These particles were spherical in shape. On extending agglomeration was observed which resulted in rod-shaped particles . Figure-6 shows EDX pattern of poly (NCA-co-AM/AMPSNa) zinc oxide nanocomposite hydrogels, which confirms the incorporation $\mathrm{ZnO}$ nanoparticles in the hydrogel matrix.
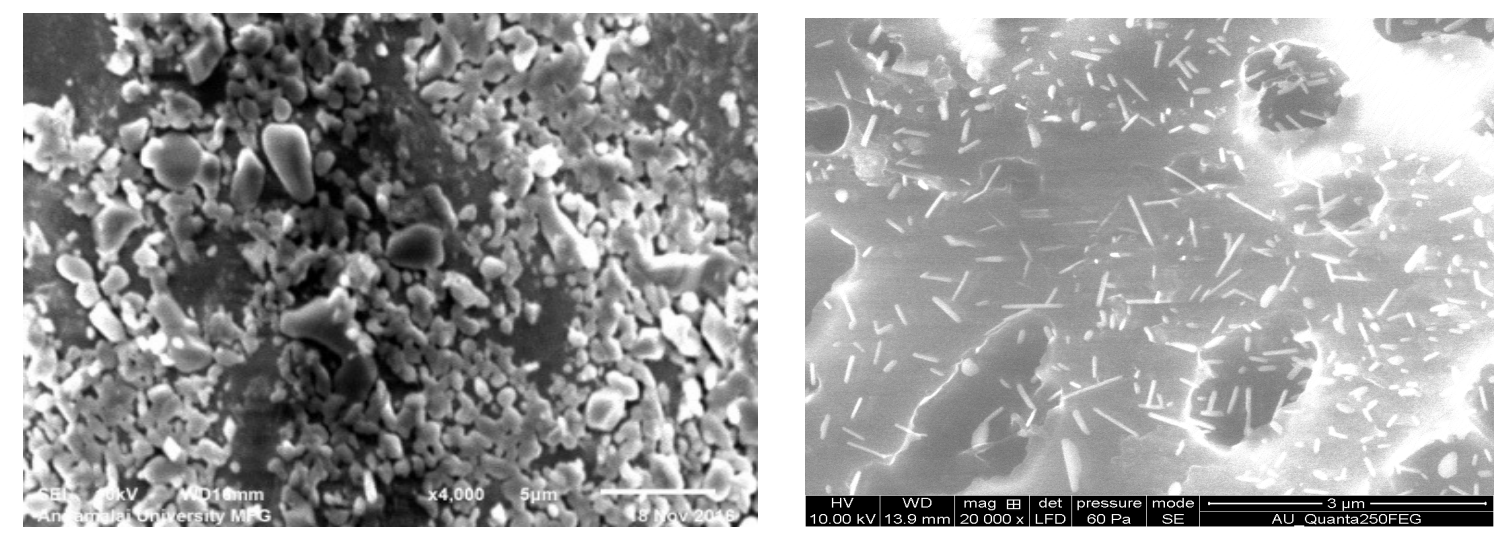

Fig.- 5: SEM Image of Poly( NCA-co-AM/AMPSNa) ZnO Nanocomposite Hydrogel

\section{Antimicrobial Activity}

Table-2 shows antibacterial as well as an antifungal activity where significant inhibition was observed with the bacterial species tested. There were no significant differences between the concentrations of the nanocomposite hydrogels used compared to no inhibition in control.The minimal concentration was potent enough to exhibit the maximum zone of inhibition with bacterial species tested (Fig.-7).Among the two fungal species tested the synthesized $\mathrm{ZnO}$ nanocomposite hydrogels were potent against Candida albicans whereas Aspergillus niger was resistant against all the concentrations (Fig.-7). These antimicrobial observations suggest for the destruction of the bacterial cells which could be due to reactive 
oxygen species such as singlet oxygen $\left({ }_{1} \mathrm{O}_{2}\right)$, hydroxyl radicals $(. \mathrm{OH}), \mathrm{H}_{2} \mathrm{O}_{2}$ and liberation of $\mathrm{Zn}^{2+}$ resulting in inhibition of bacterial growth ${ }^{26,27}$. Similarly, spore formation in Candida albicans was influenced by $\mathrm{ZnO}$ nanocomposite hydrogels. Whereas it could not be affected in Aspergillus niger with the nanocomposites concentrations tested.

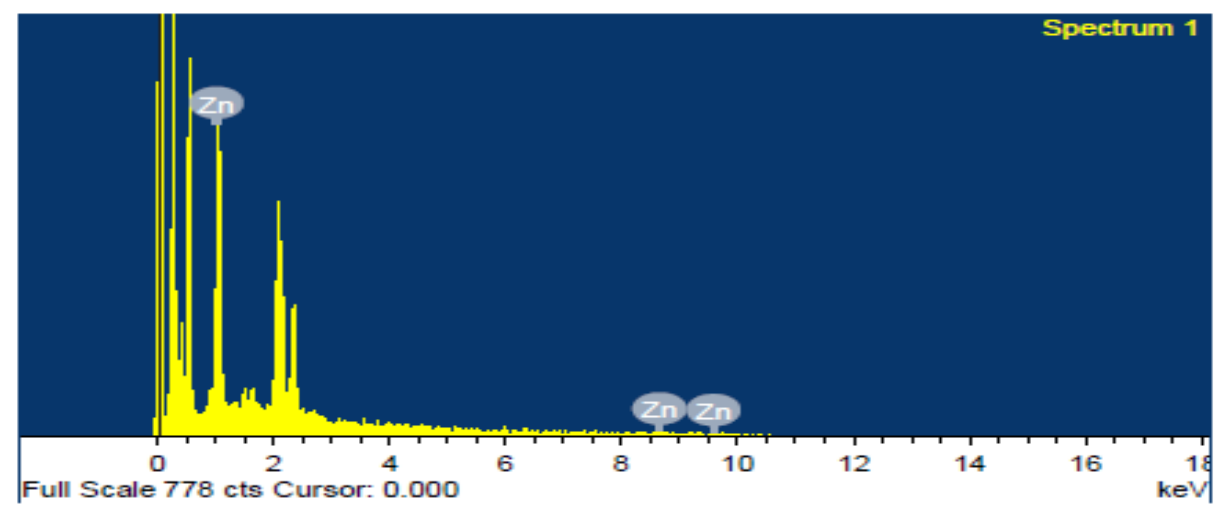

Fig. -6: EDX of Poly( NCA-co-AM/AMPSNa) ZnO Nanocomposite Hydrogel

$\mathrm{ZnO}$ is a safe material to animals and human beings. $\mathrm{ZnO}$ shows good antimicrobial activity under harsh process conditions. Due to this antimicrobial activity, it is currently used in food packaging ${ }^{28}$ and in cosmetic materials. The combination of hydrogels with $\mathrm{ZnO}$ nanoparticles having the advantages like lack of color, lower cost and UV blocking properties over the widely used Ag nanocomposites ${ }^{29,30}$. Antibacterial activity against Gram-positive and Gram-negative bacteria as well as the swelling capacity of carboxymethyl cellulose with $\mathrm{ZnO}$ nanoparticles hydrogels are reported by Hashem et al. ${ }^{28}$ and similar results have also been reported by other researchers ${ }^{31}$.It is reported that significant antifungal activity is not observed for the $\mathrm{ZnO}$ nanoparticle content as low as below $1 \% \mathrm{w} / \mathrm{w}$.
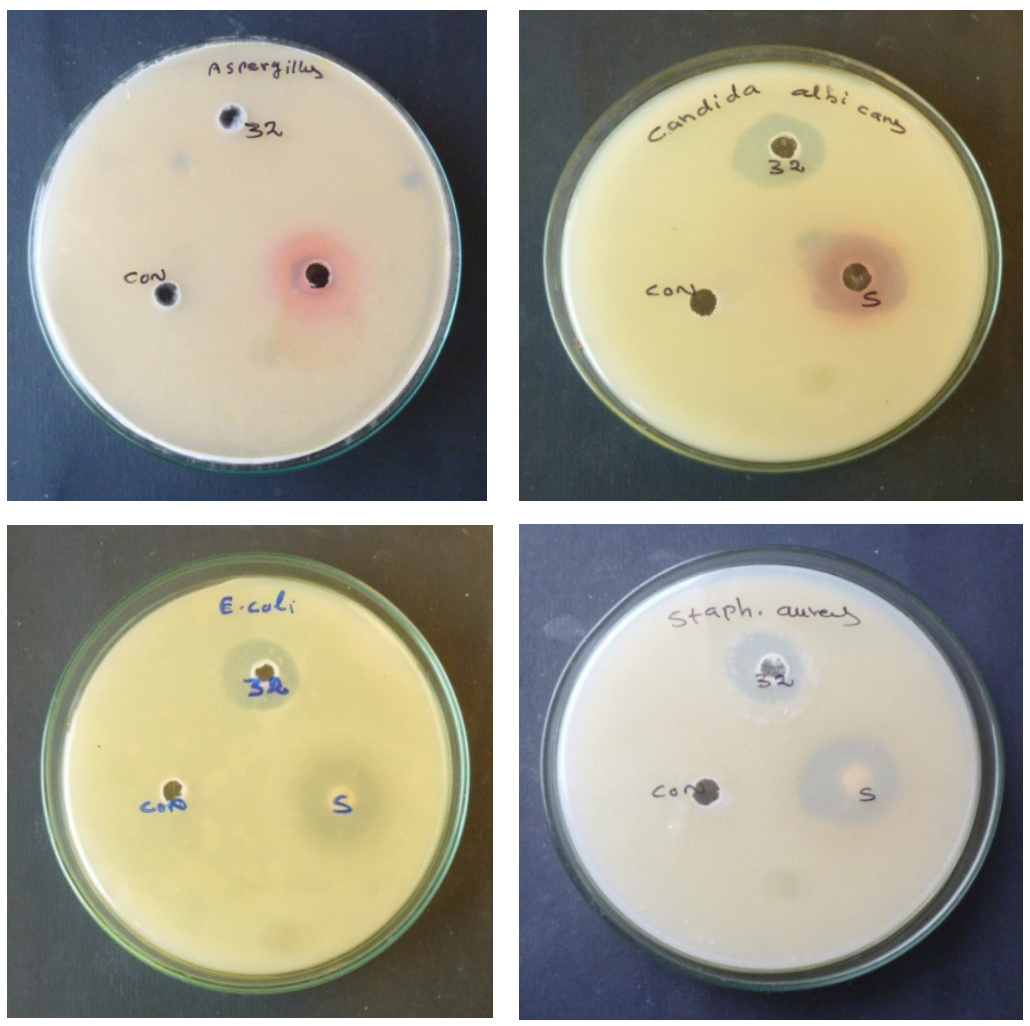

Fig.-7: Antimicrobial Studies of Poly(NCA-co-AM-co-AMPSNa) ZnO Nanocomposite Hydrogels 
RASĀYAN J. Chem.

Vol. 11 | No. 4 |1721 - 1728| October - December | 2018

Table-2: Poly(NCA-co-AM-co-AMPSNa) ZnO Nanocomposite Hydrogels

\begin{tabular}{c|c|c|c|c}
\hline \multirow{2}{*}{ S. No. (AMPSa) } & \multicolumn{4}{|c}{ Zone of inhibition (mm) } \\
\cline { 2 - 5 } & E. coli & S. aureus & Candida albicans & Aspergillus niger \\
\hline $1(0.1 \mathrm{~g})$ & 15 & 15 & 15 & NI(No. inhibition) \\
\hline $2(0.3 \mathrm{~g})$ & 15 & 15 & 14 & NI \\
\hline $3(0.5 \mathrm{~g})$ & 12 & 14 & 14 & NI \\
\hline $4(0.7 \mathrm{~g})$ & 13 & 14 & 15 & NI \\
\hline Control & NI & NI & NI & 15 \\
\hline Standard & 17 & 16 & 15 & \\
\hline
\end{tabular}

\section{CONCLUSION}

In the present study, we synthesized the poly(N-cyclohexyl acrylamide-co-acrylamide-co-2-acrylamido2-methyl propane sulphonic acid sodium salt) Zinc oxide $(\mathrm{ZnO})$ nanocomposite hydrogels by in situ free-radical copolymerization. The swelling behavior showed increasing trends as the concentration of AMPSNa increases, due to the additional osmotic pressure develops that expands the gel network further. The kinetic study showed that the hydrogel follows non-Fickian. The surface morphology of $\mathrm{ZnO}$ nanocomposite hydrogels showed the uniform dispersion of $\mathrm{ZnO}$ nanoparticles in the hydrogel matrix. EDX pattern of zinc oxide nanocomposite hydrogels, also confirms the incorporation ZnO nanoparticles in the hydrogel matrix. Among the two fungal species tested the synthesized $\mathrm{ZnO}$ nanocomposite hydrogels were potent against Candida albicans whereas Aspergillus niger was resistant against all the concentrations.

\section{REFERENCES}

1. Andrew T. Graham, and Fredric L. Buchholz, Modern Superabsorbent Polymer Technology, Wiley$\mathrm{VCH}, 1998$.

2. L. Brannon-Peppas and R. S. Harland, J. Controlled Release, 17(3), 297(1991), DOI: 10.1016/B978-0-444-88654-5.50008-X

3. Y. Li, G. Huang, X. Zhang, B. Li, Y. Chen, T. Lu, T. J. Lu and F. Xu, Adv. Funct. Mater., 23(6), 660 (2013), DOI:10.1063/1.5027460

4. T. R. Hoare and D. S. Kohane, Polymer, 49, 1993 (2008), DOI: 10.1016/j.polymer.2008.01.027

5. Y. Li, J. Rodrigues and H. Tomas, Chem. Soc. Rev., 41, 2193 (2012).

6. N. Annabi, A. Tamayol, J. A. Uquillas, M. Akbari, 1. E. Bertassoni, C. Cha, G. Camci Unal, M. R. Dokmeci, N. A. Peppas, A. Khademhosseini, Adv. Mater, 26(1), 85 (2013).

7. E. Calo, and S. Khitoryan Skiy, Eur. Polym. J., 65,252 (2015).

8. K. Lingshirn, Chem. Phys. Chem., 8,782 (2007).

9. I. Radyum, R. I. Putri and S. Siswanto, Int. J. Eng. and Tech., 12(6), 5 (2012).

10. M. Chopra, M. Bernela, P. Kaur, A. Manuja, B. Kumar and R. Thakur, Int. J. Biol. Macromol., 72, 827 (2015).

11. S. Frank and P . C. Lauterbur, Nature, 363, 334 (1993).

12. N. A. Peppas and P. Colombo, J. Controlled Release, 45, 35 (1977).

13. A. Suzuki, T. Ishii and Y. Maruyama, J. Applied Physics, 80, 131 (1996).

14. A. R. Khare and N. K. Peppas, Biomaterials, 16, 559 (1995).

15. X. Zhong, Y. X. Wang and S. C. Wang, Chem. Eng. Sci., 51, 3235 (1996).

16. N. A. Peppas and Y. Huang, Pharm. Res., 19, 578 (2002).

17. Z. Fuli, Y. Dan, G. Ruiwei, D. Liandong, D. Anjie and Z. Jianhua, Nanomaterials, 5(4), 2054 (2015).

18. P. T. Sudheesh Kumar, L. Vinoth Kumar, T. V. Anilkumar, C. Ramya, P. Reshmi, V. Unnikrishnan, A. G. Shantikumar, V. Nair, and R. Jayakumar, Appl. Mater. Interfaces, 4(5), 2618 (2012).

19. I. Clara and N. Natchimuthu, Starch, 69, 07 (2016).

20. M. Sadhghi and H. Hosseinzadeh, Turk. J. Chem., 34, 739 (2010), DOI:10.3906/kim-0910-21

21. S. Anbarasan, B. A. Brundha and P. Pazhanisamy, Rasayan J. Chem., 3(3), 571 (2010).

22. S. K. Bajpai, M. Jadaun and S. Tiwari, Carbohydr. Polym., 153,60 (2016). 
RASĀYAN J. Chem.

Vol. 11 | No. 4 |1721 - 1728| October - December | 2018

23. C. Wang, J. Lv, Y. Ren, Q. Zhou, J. Chen, T. Zhi, Z. Lu, D. Gao, Z. Ma, L. Jin, Carbohydr. Polym., 138,106 (2016).

24. L. H. Li, J. C. Deng, H. R. Deng, Z. L. Liu, L. Xin, Carbohydr. Res. 345, 994 (2010).

25. P. J. Perez Espitia, N. D. F. Ferreira Soares, J. S. Dos Reis Coimbra, N.J. De Andrade, R. S. Cruz and E. A. Alves Medeiros, Food Bio Process Tech., 5, 1447 (2012).

26. I. Perelshtein, E. Ruderman, N. Perkas, T. Tznov, J. Beddow, E. Joyce, T. J. Mason, M. Blanes, K. Molla, A. Patiola, A. J. Frenkel and A. Gedanken, J. Mater. Chem., B1, 1968 (2013).

27. A. El Shafei and A. Abou Okeil, Carbohydr. Polym., 83, 920 (2011).

28. M. Hashem, S. Sharaf, M. M. Abd El Hady and A. Hebeish, Carbohydr. Polym., 95, 421 (2013).

29. V. B. Schwartz, F. Thetiot, S. Ritz, S. Puetz, L. Choritz, A. Lappas, R. Foerch, K. Landfester and U. Jonas, Adv. Funct. Mater., 22, 2376 (2012).

30. J. Wang, H.Hu, Z. Yang, J. Wei and J. Li, Mater. Sci. Engg., C 61, 376 (2016).

31. A. Sirelkhatim, S. Mahmud, A. Seeni, N. H. M. Kaus, L. C. Ann, S. K. M. Bakhori, H. Hasan and D. Mohamad, Nano-Micro Letters, 7, 219 (2015).

[RJC-2072/2017] 